Case Report

\title{
Mechanical Ventilation Weaning in Inclusion Body Myositis: Feasibility of Isokinetic Inspiratory Muscle Training as an Adjunct Therapy
}

\author{
Leonardo Cordeiro de Souza, ${ }^{1,2}$ Josué Felipe Campos, ${ }^{2}$ Leandro Possidente Daher, ${ }^{2}$ \\ Priscila Furtado da Silva, ${ }^{2}$ Alex Ventura, ${ }^{2}$ Pollyana Zamborlini do Prado, ${ }^{2}$ Daniele Brasil, ${ }^{2}$ \\ Debora Mendonça, ${ }^{2}$ and Jocemir Ronaldo Lugon ${ }^{3}$
}

${ }^{1}$ Medical Science Post-Graduation Program, Universidade Federal Fluminense, Niterói, RJ, Brazil

${ }^{2}$ Intensive Care Division, Hospital e Clínica São Gonçalo, São Gonçalo, RJ, Brazil

${ }^{3}$ Nephrology Division, Department of Medicine, Medical School, Universidade Federal Fluminense, Niterói, RJ, Brazil

Correspondence should be addressed to Leonardo Cordeiro de Souza; leonardo.uti@gmail.com

Received 8 May 2014; Accepted 12 July 2014; Published 24 July 2014

Academic Editor: Nicolas Nin

Copyright (C) 2014 Leonardo Cordeiro de Souza et al. This is an open access article distributed under the Creative Commons Attribution License, which permits unrestricted use, distribution, and reproduction in any medium, provided the original work is properly cited.

\begin{abstract}
Inclusion body myositis is a rare myopathy associated with a high rate of respiratory complications. This condition usually requires prolonged mechanical ventilation and prolonged intensive care stay. The unsuccessful weaning is mainly related to respiratory muscle weakness that does not promptly respond to immunosuppressive therapy. We are reporting a case of a patient in whom the use of an inspiratory muscle-training program which started after a two-week period of mechanical ventilation was associated with a successful weaning in one week and hospital discharge after 2 subsequent weeks.
\end{abstract}

\section{Introduction}

In 1971, the term "inclusion body myositis" (IBM) was coined to describe a subset of patients with chronic myositis, whose muscle biopsy showed besides inflammation, muscle fibres containing vacuoles and abnormal filaments, and characteristic inclusions in cytoplasm and nucleus [1]. The inclusion body myositis is grouped with dermatomyositis and polymyositis as idiopathic inflammatory myopathies [2]. The disease is characterized by a proximal myopathy, which progressively leads to functional disability. It is more common in adults in their fifties $[1,2]$. Respiratory complications can reach a prevalence of $45 \%$. Weakness/fatigue of respiratory muscles with interstitial pneumonia and dysphagia are the main causes of death [2-4]. The use of mechanical ventilation is required in most cases, but weaning is hardly achieved $[4,5]$. We are reporting a case in whom an inspiratory muscle training program (IMT) using an isokinetic electronic load device which started after a two-week period of mechanical ventilation was associated with a successful weaning in one week.

\section{Case Report}

A 43-year-old male was admitted to the intensive care of the hospital with symmetrical muscle weakness in the pelvic and scapular girdles. He reported a history of GuillainBarré syndrome in 2005 without motor sequelae. His initial laboratory exams were haemoglobin of $16.1 \mathrm{~g} / \mathrm{dL}$; leukocytes of $13,030 / \mathrm{mm}^{3}$ with $3 \%$ young forms and $13 \%$ of lymphocytes; urea of $23 \mathrm{mg} / \mathrm{dL}$; creatinine of $0.34 \mathrm{mg} / \mathrm{dL} ; \mathrm{Na}$ of $131 \mathrm{mEq} / \mathrm{L}$; $\mathrm{K}$ of $5.5 \mathrm{mEq} / \mathrm{L} ; \mathrm{Cl}$ of $97 \mathrm{mEq} / \mathrm{L}$; AST of $51 \mathrm{U} / \mathrm{L}$; ALT of $49 \mathrm{U} / \mathrm{L}$; lactate of $1.1 \mathrm{mEq} / \mathrm{L}$; LDL of $926 \mathrm{U} / \mathrm{L}$; CK of $145 \mathrm{U} / \mathrm{L}$; and CRP of $4.6 \mathrm{mg} / \mathrm{dL}$.

$\mathrm{He}$ evolved with acute respiratory failure type II $\left(\mathrm{PaO}_{2}\right.$ $<60 \mathrm{mmHg}$ and $\mathrm{PaCO}_{2}>45 \mathrm{mmHg}$ ) requiring orotracheal intubation and mechanical ventilation that was set on a pressure controlled mode. His cerebrospinal fluid showed 


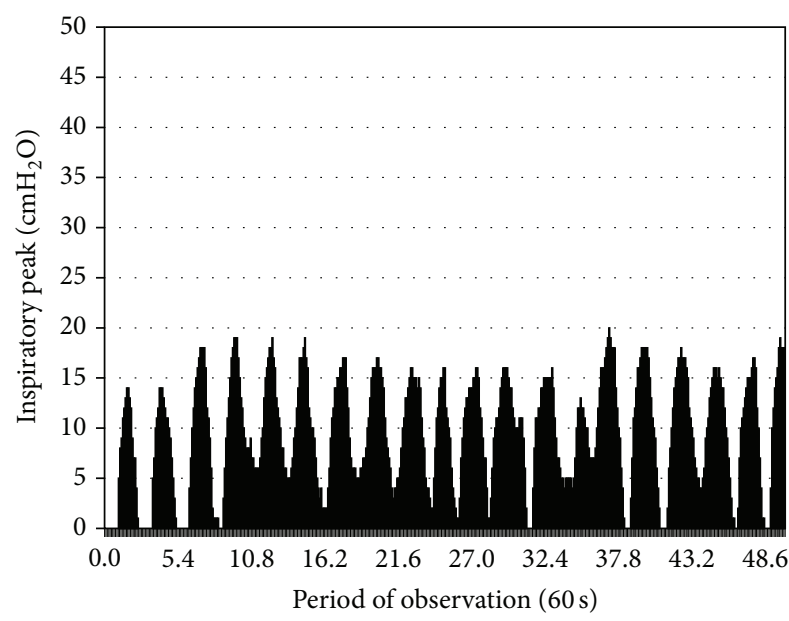

(a)

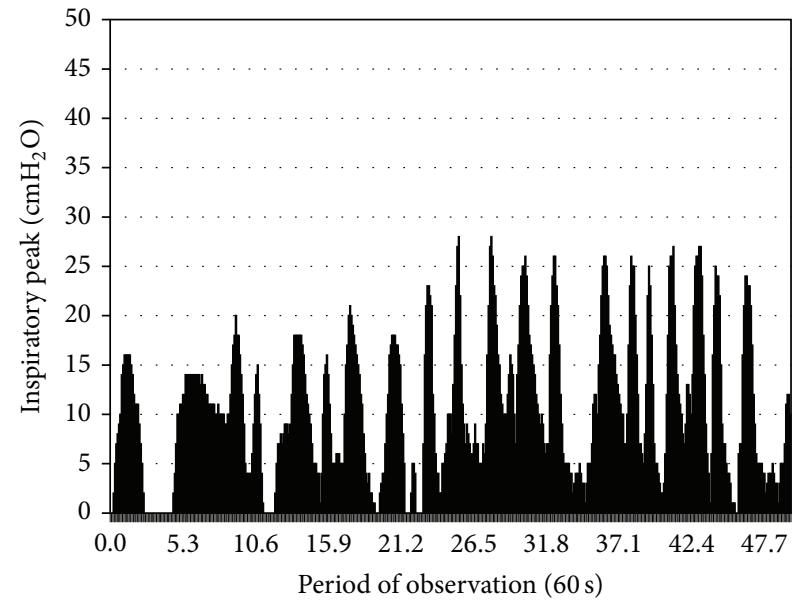

(b)

FIGURE 1: Graphics of inspiratory peaks by TIE index method. (a) At start of program on mechanical ventilation dependence; (b) 14 days after treatment associated with successful weaning.

the presence of lymphocytes, monocytes, neutrophils, and macrophages, blood cultures were negative for bacterial or fungal agents, and serological tests for toxoplasmosis, herpes, varicella, and HIV were all negative. A deltoid muscle biopsy showed a mononuclear interstitial inflammatory infiltrate with fibres exhibiting rimmed vacuoles, findings that were thought to be compatible with the diagnosis of inclusion body myositis.

During his stay in the ICU, he received a course of intravenous immunoglobulin $(0.4 \mathrm{~g} / \mathrm{kg}$ per day for 5 days) and oral prednisone ( $1 \mathrm{mg} / \mathrm{kg}$ per day) without improvement [4]. In the same period, he developed nosocomial pneumonia and septic shock and was managed with vasoactive amines and intravenous antibiotic therapy (meropenem combined with polymyxin $B$ ).

After three unsuccessful weaning trials, the patient was tracheotomised on the 14th day of intubation and transferred to the prolonged ventilation unit. Following hemodynamic stabilization and infection control, azathioprine $150 \mathrm{mg}$ per day [4] was started in association with a inspiratory muscle training (IMT) program using an isokinetic electronic load device (POWERbreathe K-5, London, UK), 2 daily sessions of 30 respiratory cycles as previously described [9], with a load of $30 \%$ of the expected maximal inspiratory pressure as described elsewhere [10-12]. Load and intensity were reassessed weekly using commercial software (BreatheLink, POWERbreathe Co., London, UK). During the period of treatment, the patient comfortably remained under pressure support ventilation (frequency $<30$ ). The IMT program was accompanied by an early mobilization protocol (active member exercising in bed followed by resistance exercising against gravity at the bedside, evolving to standing position and cycle ergometer activity) [13].

At the start of the new therapeutic program, the measured respiratory parameters of the patient were static compliance of $55 \mathrm{~mL} / \mathrm{cm} \mathrm{H}_{2} \mathrm{O}, \mathrm{SpO}_{2}$ of $95 \%\left(\mathrm{FIO}_{2} 35 \%\right)$, breathing frequency of $21 \mathrm{bpm}$, tidal volume of $0.390 \mathrm{~L}$, an $\mathrm{f} / \mathrm{Vt}$ index
TABle 1: Compromise of muscular force in the lower limbs by Medical Research Council (MRC).

\begin{tabular}{lcc}
\hline Muscles & $\begin{array}{c}\text { Before treatment } \\
\text { Left/right }\end{array}$ & $\begin{array}{c}\text { After treatment } \\
\text { Left/right }\end{array}$ \\
\hline Biceps brachii & $3 / 3$ & $5 / 5$ \\
Triceps brachii & $1 / 1$ & $4 / 4$ \\
Extensor carpi radialis & $3 / 3$ & $5 / 5$ \\
Iliopsoas & $1 / 1$ & $4 / 4$ \\
Quadriceps femoris & $1 / 1$ & $4 / 4$ \\
Tibialis anterior & $2 / 2$ & $4 / 4$ \\
\hline Total & 22 & 52
\end{tabular}

MRC scoring system. 0: no movement; 1: palpable contraction, no visible movement; 2: movement but only with gravity eliminated; 3: movement against gravity; 4: movement against resistance but weaker than normal; 5: normal power. [6].

of $54 \mathrm{bpm} / \mathrm{L}, \mathrm{P} 0.1$ of $4.66 \mathrm{~cm} \mathrm{H}_{2} \mathrm{O}$, MIP of $20 \mathrm{~cm} \mathrm{H}_{2} \mathrm{O}(17 \%$ of the expected value of $118 \mathrm{~cm} \mathrm{H}_{2} \mathrm{O}$ ), and timed inspiratory effort (TIE) index of $0.54 \mathrm{~cm} \mathrm{H}_{2} \mathrm{O} / \mathrm{sec}$ ( $~ 50 \%$ of the expected value). The muscle function evaluation of the patient at the beginning of the training program showed an Medical Research Council (MRC) score of 22 (see Table 1), while the correspondent values for the degree of independence of the patient as assessed by the motor domain of the Functional Independence Measure (FIM) score was 14; see Table 2.

After two weeks of IMT, the MIP increased to $28 \mathrm{~cm} \mathrm{H}_{2} \mathrm{O}$, the TIE index to $1.09 \mathrm{~cm} \mathrm{H}_{2} \mathrm{O} / \mathrm{sec}$, and a partial respiratory independence was achieved (nocturnal pressure support ventilation was provided) [4]. After four weeks, MIP was $50 \mathrm{~cm} \mathrm{H}_{2} \mathrm{O}$; see Figure 1. By that time, the load employed with the power breath device was $15 \mathrm{~cm} \mathrm{H}_{2} \mathrm{O}$. He progressed to decannulation and was maintained on nocturnal noninvasive ventilation to avoid hypoventilation and carbonarcosis. By the time of hospital discharge, he was under IMT twice a day 
TABLE 2: Evaluation of self-care, sphincters, and mobility by functional independence measure (FIM).

\begin{tabular}{lcc}
\hline Parameters & Before treatment & After treatment \\
\hline (1) Eating & 1 & 7 \\
(2) Grooming & 1 & 7 \\
(3) Bathing/showering & 1 & 6 \\
(4) Dressing upper body & 1 & 6 \\
(5) Dressing lower body & 1 & 6 \\
(6) Toileting & 1 & 7 \\
(7) Bladder management & 2 & 7 \\
(8) Bowel management & 2 & 7 \\
mobility & & 7 \\
(9) Transfers: & 1 & 7 \\
bed/chair/wheelchair & 1 & 7 \\
(10) Transfers: toilet & 1 & 7 \\
(11) Locomotion: & 1 & 81 \\
walking/wheelchair & 14 & \\
(12) Locomotion: stairs & & \\
\hline Total & & \\
\hline
\end{tabular}

FIM scoring. 7: complete independence, fully independent; 6: modified independence requiring the use of a device but no physical help; 5 : supervision requiring only standby assistance or verbal prompting or help with setup; 4: minimal assistance requiring incidental hands-on help only (subject performs $>75 \%$ of the task); 3 : moderate assistance; subject still performs $50-75 \%$ of the task; 2: maximal assistance; subject provides less than half of the effort (25-49\%); and 1: total assistance; subject contributes $<25 \%$ of the effort or is unable to do the task $[7,8]$.

with a load of $17 \mathrm{~cm} \mathrm{H}_{2} \mathrm{O}$ and walking $380 \mathrm{~m}$ independently, but under supervision, and climbing a flight of stairs. His MRC score was 52 (see Table 1) and the motor FIM score was 81 (see Table 2). After 6 months of hospital discharge, the patient remains on a regular use of the inspiratory load device and continues to improve his muscle strength. He is now gradually coming back to his daily activities.

\section{Discussion}

We are reporting a case of body inclusion myositis in which the definite diagnosis was obtained early in the course of the disease. Following previous recommendations [1,3-5], therapy was promptly started with intravenous immunoglobulin and steroids; the maintenance drug chosen was azathioprine. The experience with the treatment of this entity has been disappointing $[1,4,5]$. Unsuccessful weaning represents a major obstacle to patient recovery and is associated with a high rate of respiratory infection and a fatal outcome [2$4,14]$. Although effective in the management of the subjacent process that precipitated the disorder, immunosuppressive agents conceivably do not have any direct action upon the recovery of muscle function. It is plausible that the long period required for recovery of muscle strength may play a role in the weaning failure, emergency of infections, and the dismal prognosis of the disorder. Therefore, the use of a respiratory muscle training program could have a favourable impact on the outcome of the disease $[9,15,16]$. Indeed, the use of inspiratory muscle training has been found to be helpful in a variety of scenarios in which the mechanical ventilation weaning is troublesome $[15,17,18]$.

We resorted to an isokinetic electronic load device using a protocol of endurance gain (higher number of repetitions using submaximal loads) given that the respiratory muscles display a large number of type I fibres, which are resistant to fatigue $[9,15,16]$. During the IMT program the patient showed no respiratory or hemodynamic changes that would prevent its continuation. The combination of the two strategies, one addressing the treatment of the acute immunological pathway and the other the recovery of muscle function, was associated with a successful weaning from mechanical ventilation, hospital discharge, and return to daily activities.

It is our view that the appropriate cleaning of the artificial airway, the correct positioning of the patient, and his collaboration were all essential to the success of the muscle training intervention.

In conclusion, the use of an inspiratory load device in association with the conventional therapy with immunosuppressive agents in the reported case was associated with an increase in the strength of the inspiratory muscles resulting in a favourable outcome. This is in line with previous reports above mentioned [15], but further studies are necessary to establish the exact role of IMT in the process of weaning from the ventilator these patients.

\section{Conflict of Interests}

Leonardo Cordeiro de Souza, Josué Felipe Campos, Leandro Possidente Daher, Priscila Furtado, Alex Ventura, Pollyana Zamborlini do Prado, Daniele Brasil, Debora Mendonça and Jocemir Ronaldo Lugon state that they do not have any potential conflict of interests to disclose.

\section{Authors' Contribution}

Leonardo Cordeiro de Souza and Jocemir Ronaldo Lugon equally contributed to the design and paper preparation. Josué Felipe Campos, Leandro Possidente Daher, Priscila Furtado, Alex Ventura, Pollyana Zamborlini do Prado, Daniele Brasil, and Debora Mendonça helped regarding the patient care and the case report.

\section{Acknowledgments}

The authors are thankful to the respiratory physiotherapists (especially to Clarine Mendes, Erika Cristine Cordeiro, Monica Lourenço, Leandro Daher, Wanderlei Augusto Junior, Priscila Furtado, and Josué Felipe Campos) and physicians of the intensive care unit of the Hospital and Clínica São Gonçalo for their collaboration to our study.

\section{References}

[1] R. C. Griggs, V. Askanas, S. DiMauro et al., "Inclusion body myositis and myopathies," Annals of Neurology, vol. 38, no. 5, pp. 705-713, 1995. 
[2] J. W. Teener and E. C. Raps, "Evaluation and treatment of respiratory failure in neuromuscular disease," Rheumatic Disease Clinics of North America, vol. 23, no. 2, pp. 277-292, 1997.

[3] I. Marie, P. Hatron, E. Hachulla, B. Wallaert, U. MichonPasturel, and B. Devulder, "Pulmonary involvement in polymyositis and in dermatomyositis," Journal of Rheumatology, vol. 25, no. 7, pp. 1336-1343, 1998.

[4] A. Selva-O’Callaghan, L. Sanchez-Sitjes, X. Muñoz-Gall et al., "Respiratory failure due to muscle weakness in inflammatory myopathies: maintenance therapy with home mechanical ventilation," Rheumatology, vol. 39, no. 8, pp. 914-916, 2000.

[5] R. Cohen, S. Lipper, and D. R. Dantzker, "Inclusion body myositis as a cause of respiratory failure," Chest, vol. 104, no. 3, pp. 975-977, 1993.

[6] Medical Research Council, Aids to the Investigation of Peripheral Nerve Injuries. War Memorandum, HMSO, London, UK, 2nd edition, 1943.

[7] C. V. Granger, B. B. Hamilton, J. M. Linacre, A. W. Heinemann, and B. D. Wright, "Performance profiles of the functional independence measure," The American Journal of Physical Medicine and Rehabilitation, vol. 72, no. 2, pp. 84-89, 1993.

[8] J. M. Linacre, A. W. Heinemann, B. D. Wright, C. V. Granger, and B. B. Hamilton, "The structure and stability of the functional independence measure," Archives of Physical Medicine and Rehabilitation, vol. 75, no. 2, pp. 127-132, 1994.

[9] S. R. Kulkarni, E. Fletcher, A. K. McConnell, K. R. Poskitt, and M. R. Whyman, "Pre-operative inspiratory muscle training preserves postoperative inspiratory muscle strength following major abdominal surgery-a randomised pilot study," Annals of the Royal College of Surgeons of England, vol. 92, no. 8, pp. 700-705, 2010.

[10] L. C. de Souza, C. T. da Silva Jr., and J. R. Lugon, "Evaluation of the inspiratory pressure using a digital vacuometer in mechanically ventilated patients: analysis of the time to achieve the inspiratory peak," Respiratory Care, vol. 57, no. 2, pp. 257262, 2012.

[11] L. C. de Souza, C. T. da Silva Jr., J. R. Almeida, and J. R. Lugon, "Comparison of Maximal inspiratory pressure, tracheal airway occlusion pressure, and its ratio in the prediction of weaning outcome: impact of the use of a digital vacuometer and the unidirectional valve," Respiratory Care, vol. 57, no. 8, pp. 12851290, 2012.

[12] L. C. de Souza, F. S. Guimarães, and J. R. Lugon, "Evaluation of a new index of mechanical ventilation weaning: the timed inspiratory effort," Journal of Intensive Care Medicine, 2013.

[13] H. J. Engel, D. M. Needham, P. E. Morris, and M. A. Gropper, "ICU early mobilization: from recommendation to implementation at three medical centers," Critical Care Medicine, vol. 41, no. 9, supplement 1, pp. S69-S80, 2013.

[14] J.-M. Boles, J. Bion, A. Connors et al., "Weaning from mechanical ventilation," European Respiratory Journal, vol. 29, no. 5, pp. 1033-1056, 2007.

[15] A. D. Martin, B. K. Smith, P. D. Davenport et al., "Inspiratory muscle strength training improves weaning outcome in failure to wean patients: a randomized trial," Critical Care, vol. 15, no. 2, article R84, 2011.

[16] B. M. Bissett, I. A. Leditschke, J. D. Paratz, and R. J. Boots, "Protocol: Inspiratory muscle training for promoting recovery and outcomes in ventilated patients (IMPROVe): a randomised controlled trial," BMJ Open, vol. 2, no. 2, Article ID e000813, 2012.
[17] L. Moodie, J. Reeve, and M. Elkins, "Inspiratory muscle training increases inspiratory muscle strength in patients weaning from mechanical ventilation: a systematic review," Journal of Physiotherapy, vol. 57, no. 4, pp. 213-220, 2011.

[18] L. P. Cahalin, R. Arena, M. Guazzi et al., "Inspiratory muscle training in heart disease and heart failure: a review of the literature with a focus on method of training and outcomes," Expert Review of Cardiovascular Therapy, vol. 11, no. 2, pp. 161177, 2013. 


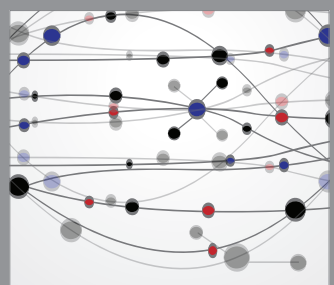

The Scientific World Journal
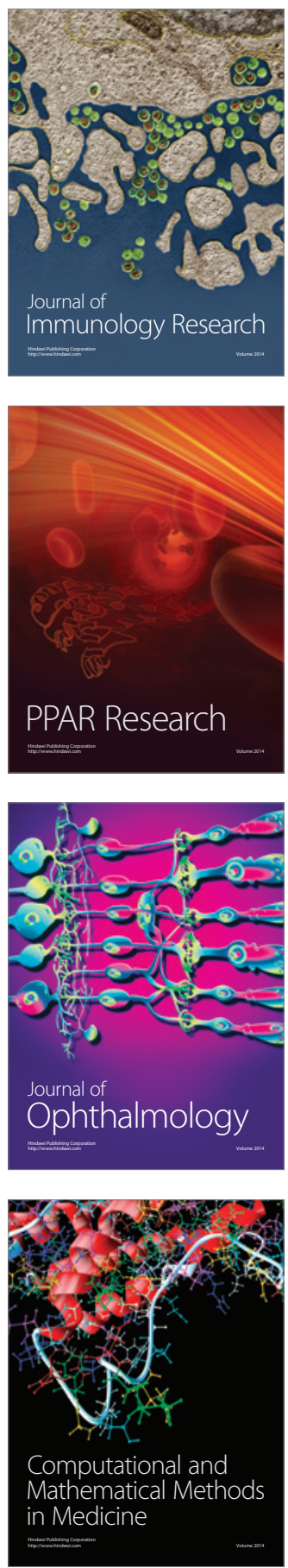

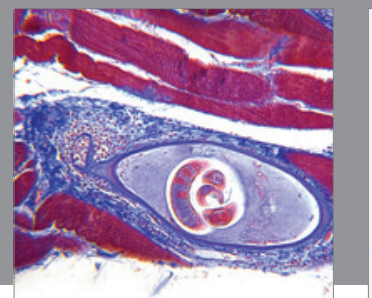

Gastroenterology

Research and Practice
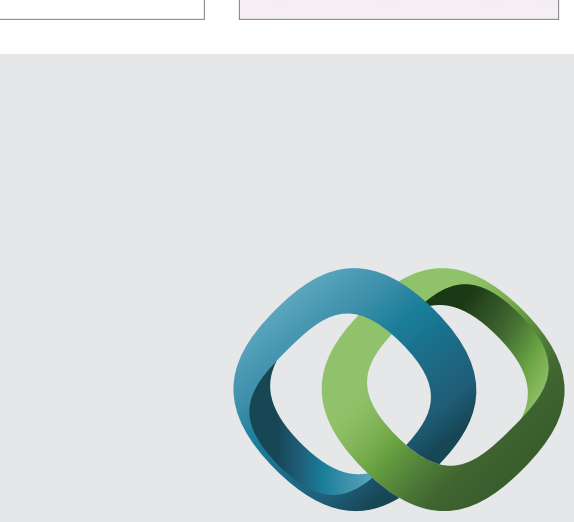

\section{Hindawi}

Submit your manuscripts at

http://www.hindawi.com
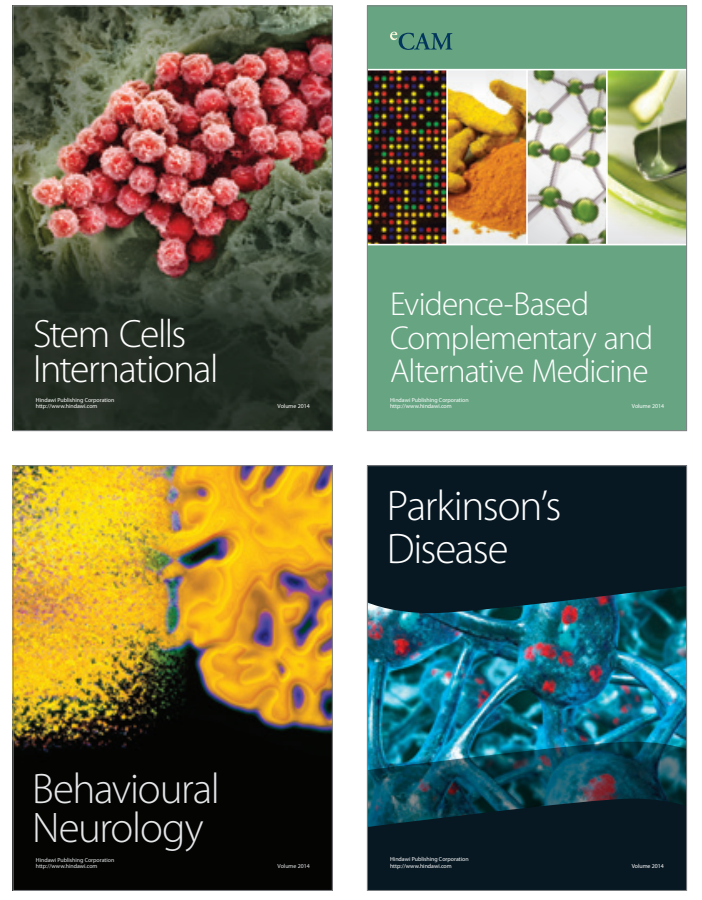
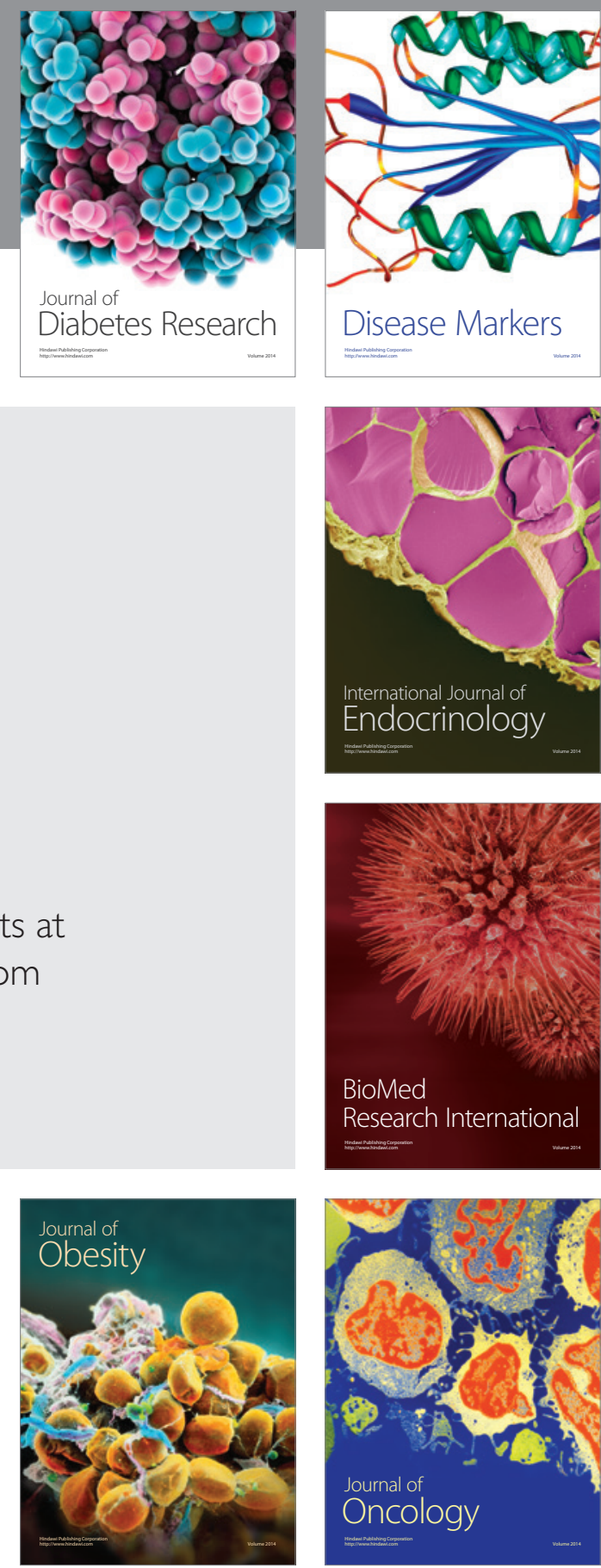

Disease Markers
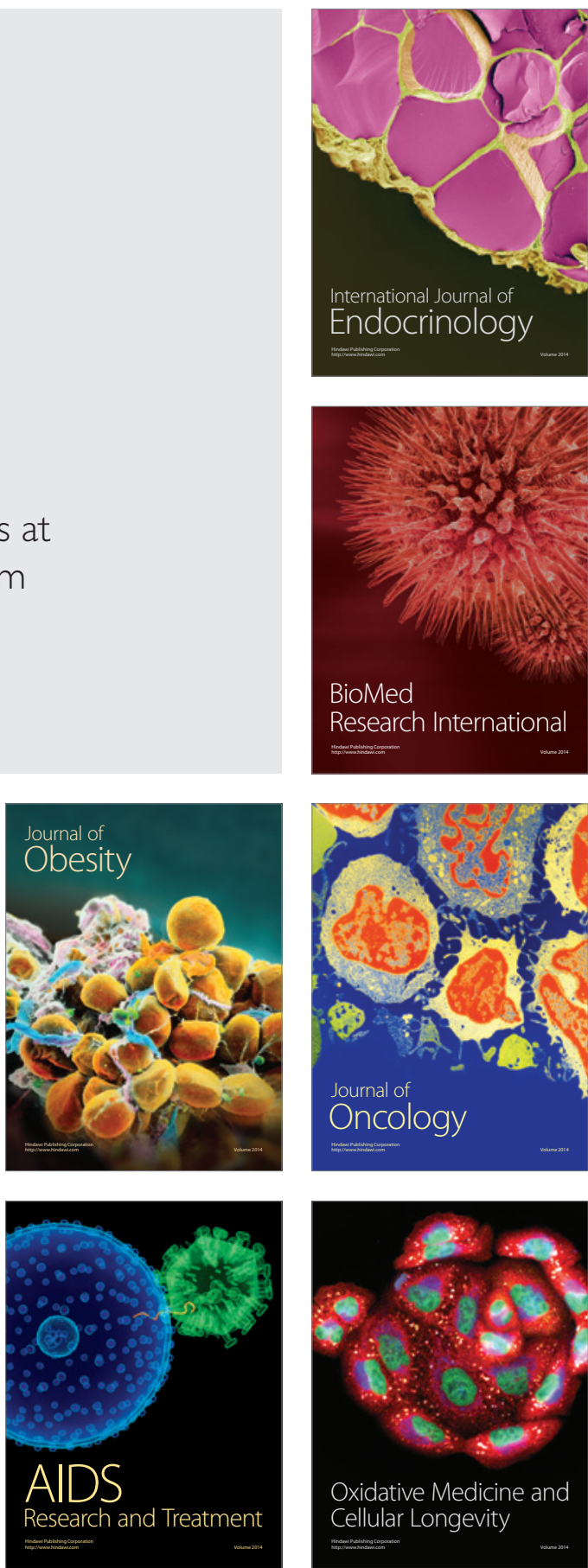